\title{
Modern Health Worries and the Personality Disorders: Two Studies Using Different Measures
}

\author{
Adrian Furnham \\ Norwegian Business School (BI), Nydalveien, Olso, Norway \\ Email:adrian@adrianfurnham.com
}

How to cite this paper: Furnham, A (2021) Modern Health Worries and the Personality Disorders: Two Studies Using Different Measures. Health, 13, 217-237. https://doi.org/10.4236/health.2021.133019

Received: February 7, 2021

Accepted: March 8, 2021

Published: March 11, 2021

Copyright $\odot 2021$ by author(s) and Scientific Research Publishing Inc. This work is licensed under the Creative Commons Attribution International License (CC BY 4.0).

http://creativecommons.org/licenses/by/4.0/

\begin{abstract}
This paper reports on two studies using different measures of both Modern Health Worries (MHW) and the Personality Disorders (PDs) to establish the relationship between the two concepts. Study 1 used the PID- 5 which is a measure of maladaptive personality traits and the extended 40 item MHW scale. Study 2 used the original 28 item measure of MHW and PDs as measured by the Coolidge Axis-II Inventory-Short Form: SCATI. In study 1 a regression on the total MHW scale accounted for 14\% of the variance: those who scored higher on Antagonism and Negative Affect had higher MHW scores. In the study 2 regressions showed four variables consistently related to MHW: sex (females with higher scores), optimism, political beliefs (left wing liberals with higher scores) and those with Cluster B personality disorders (dramatic, overly emotional, erratic). There was enough overlap in the two studies to conclude that various PDs mainly from Cluster B (Moving Against others) were modestly related to MHW as predicted. Limitations and implications are considered.
\end{abstract}

\section{Keywords}

Mental Health Worries, Personality Disorders, Dark-Side, Sex

\section{Introduction}

Modern Health Worries (MHW) are defined as beliefs about "perceived risk to personal health from technological changes and features of modern life" ([1], p. 778). The concept of MHW was proposed by Petrie, Silvertsen, Hysing, Broadbent, Moss-Morris, Eriksen and Ursin [2], who noted that many individuals believe their health is threatened by various aspects of modernity. They suggested 
that as the perceptions of personal vulnerability are increased, subjective feelings of health are decreased.

Petrie et al. [2] developed a 27-item MHW scale, which has been added to by other researchers and there are factor analytic studies which have attempted to identify underlying dimensions [3]. Various researchers have examined the psychometric properties of the scale such as that by Spangenberg, Zenger, Rief, Brahler and Glaesmer [4] who found a clear four factor structure based on the original questionnaire.

This study is concerned with PD and other individual difference correlates of MHWs. Various studies have suggested the MHWs are associated with conditions like depression [5] as well as neuroticism [6], health anxiety [7] and somatosensory amplification. Correlations are nearly always significant and in the predicted direction but relatively small.

This paper reports on two studies both using international samples but primarily from America and to a lesser extent India. Participants were recruited via Amazon Mechanical Turk (MTurk), an online market for enlisting workers to participate in research. Data collected from MTurk has been found to have similar levels of reliability with traditional recruitment methodologies, and the sample's diversity was also found to be more superior to those of student samples [8].

\section{Studies on MHW}

Work on MHW has been universal taking place in many countries. There is now a rapidly growing literature on MHW including studies conducted in America [6], Denmark [9], England [10] [11], Germany [5] [12], Hungary [13], the Netherlands [14], Norway [15], Sweden [16], Taiwan [17], and Turkey [18]. Many findings have been replicated which provides confidence in the results of this important research topic.

The MHW literature has steadily grown since Petrie et al.'s [1] [2] studies [7] [13] [19]-[28]. Many studies have examined mental health correlates of MHW. Andersen and Jensen [9] found as hypothesized that MHW scores were significantly positively associated with visits to a GP. Indeed, there were $20 \%$ more visits among people the highest quartile of the MHW scale. In a large German representative sample Rief et al. [5] found as predicted that MHWs were significantly associated with depression, symptom reporting and lower health-related quality of life. In a Hungarian sample, Freyler, Kohegyi, Koteles, Kokonyei and Bardos [29] found MHWs related to somatosensory amplification and health anxiety in adolescents.

In a recent large-scale study $(N=5933)$ in the Netherlands, Baliatsas et al. [14] found higher MHWs were significantly associated with increased self-reported prevalence and duration of Non-Specific Physical Symptoms (NSPS), symptomrelated healthcare utilization, GP-registered NSPS, alternative therapy consultations and lower sleep quality and quality of life. These results were statistically 
mediated by perceived environmental sensitivity.

Studies have also shown predictable personality correlates of MHW [3] [6] [10]. Over the past 20 years there have been various reviews that have looked at the relationship between the Five Factor trait model and the DSM PDs [30]. They have shown considerable overlap particularly with Neuroticism (positively) and Agreeableness and Conscientiousness (negatively). People with PDs seem to have difficulty maintaining relationships and have poor self-awareness. There are good reasons to suppose the PD traits are associated with MHWs. Studies that have looked at individual correlates of MHW suggest that high scores are associated with poor emotional coping and idiosyncratic beliefs and ideas. There are many different measures of the PDs and this paper uses two very different measures of the PDs [31].

\section{Study 1}

This study used the Personality Inventory for DSM-5 (PID-5) which is a 220 item self-rated personality trait assessment scale for adults age 18 and older. It is a new measure devised in response to the many debates about the classification of the personality disorders. It assesses 25 personality trait facets including with each trait facet consisting of 4 to 14 items. Specific groups of three facets can be combined to yield indices of the five broader trait domains of Negative Affect, Detachment, Antagonism, Disinhibition, and Psychoticism. Each item asks the individual to rate how well the item describes him or her generally. Negative $A f$ fect is defined as Emotional Lability, Anxiousness, and Separation Insecurity. Detachment concerns Withdrawal, Anhedonia, and Intimacy Avoidance. Antagonism is about Manipulativeness, Deceitfulness, and Grandiosity. Disinhibition concerns Irresponsibility, Impulsivity, and Distractibility; while Psychoticism concerns Unusual Beliefs \& Experiences, Eccentricity, and Perceptual Dysregulation. It was predicted that we would replicate the essential four factors from the MHW scale (H1). We also predicted that Negative Affect (H2), Antagonism (H3) and Psychoticism (H4) would be positively correlated with the total MHW score.

\section{Method}

\subsection{Participants}

The final sample for this study comprised 130 women and 129 men (age $M=$ $36.36, S D=11.12)$. The majority of participants were White $(54.1 \%)$, while the remainders were Asian (25.1\%), multiracial (18.9\%), or some other ethnic group (1.9\%). In terms of educational qualifications, $8.1 \%$ had completed secondary schooling, $23.9 \%$ had a post-secondary qualification, $42.5 \%$ had an undergraduate degree, and $25.5 \%$ had a postgraduate degree. They also answered a number of questions on how religious they were $(1=$ Not at all to $10=$ Very $)$ and on the same scale how healthy, happy and successful they were. They were also asked various Yes/No questions: "Are you a worrier?", "Have you ever had 
treatment for a mental disorder?", as well as "Have you ever tried Alternative Medicine treatments?", "Do you think they work?" and "What is your political orientation?" ( 1 = Very Conservative to 9 = Very Radical). These items have been shown in previous research to be related to MHW [10].

\subsection{Measures}

Maladaptive Personality Traits. To measure maladaptive personality traits, we used the Personality Inventory for DSM-5 (PID-5) [32]. This is a 220-item selfreport inventory that assesses the maladaptive personality traits proposed in Section III of DSM-5. The measure taps 25 maladaptive personality traits, organised based on factor analytic evidence into five broad domains. Each trait is measured by 4 to 14 items, with responses made on an 8 -point scale $(0=V e r y$ false or often false, $8=$ Very true or often true). Facet scores were computed as the mean of items associated with each facet. PID-5 scores have been shown to have good internal consistency and factorial validity [33]. Cronbach's $\alpha$ in the current sample for the PID-5 domain scale scores were good, while facet scores were acceptable-to-good.

Modern Health Worries. Participants completed the MHW scale [2], a 27-item measure in which respondents rate their concerns about aspects of modern life affecting their health. Items were rated on a 5 -point scale $(1=$ No concern, $5=$ Extreme concern). Although factor analytic results indicate that lower-order dimensionality [3], subscale scores tend to have poor internal consistencies and are typically inter-correlated. Some scholars show a preference for a total modern health worries scores, which is what we computed in the present study as the mean of all 27 items. Higher scores on this scale indicate greater modern health concern. Total scores on this scale have been shown to have good psychometric properties [2]. In the present study, Cronbach's $\alpha$ for this scale was 0.96 .

Demographics. Participants provided their demographic details, consisting of sex, age, ethnicity, and highest educational qualification. They also rated on a five-point scale how happy, healthy and successful they were, as well as their religious practices and political beliefs.

\subsection{Procedure}

Ethics approval was sought and gained from the appropriate committee. The present data was collected online via Amazon's Mechanical Turk (MTurk), a crowd sourcing Internet site that allows individuals to complete online tasks for monetary compensation. The study was described to potential participants as an investigation of personality and attitudes toward world events. After providing informed consent, participants were directed to the measures described above (as well as a measure of belief in conspiracy theories not analysed here) [34], which were presented in an anonymous form and in random order via the randomisation function with Qualtrics, which hosted the survey. In exchange for 
completing the survey, participants were paid \$1.00. Participants with large amounts of missing data $(N=17)$ were excluded from the dataset.

\section{Results}

\subsection{Preliminary Analyses}

Women $(M=3.08, S D=0.99)$ and men $(M=2.98, S D=0.93)$ had similar MHW scores. The mean difference between sexes was 0.10 and the $95 \%$ confidence interval for the estimate population mean difference was between -0.34 and 0.13. An independent samples $t$-test showed that the difference between women and men was not significant, $t(247)=0.87, p=0.383, d=0.10$. In addition, the correlation between MHW scores and respondent age was not significant, $r=-0.04, p=0.535$. All further analyses were, therefore, conducted the total, pooled sample.

We also correlated the total MHW score with various of the personal questions. They showed that more religious people had higher MHW $(r=0.32)$ but that it was unrelated to political orientation $(r=0.01)$. MHW scores were overall with rating oneself as healthy $(r=0.16)$, happy $(r=0.18)$, successful $(r=0.24)$ and not being a worrier $(r=0.16)$.

\subsection{Modern Health Worries}

Table 1 shows the mean item scores and standard deviations for the MHWs scale, as wells as means for Furnham's [3] and Jeswani and Furnham's [22] studies which used the extended version, and for Petrie et al.'s [2] study using the original items. The sum score was $68.45(S D=17.84)$ out of a possible score of 135. The mean score for the Jeswani and Furnham [22] scale was 2.80, where for this study it was 2.44. Results are relatively similar to previous research, which consistently finds air pollution, depletion of the ozone layer, and traffic fumes in the top 5 worries.

\subsection{Factor Analysis}

Previous studies have factor-analysed the MHW scale with various results (see Table 2). The data were treated to a VARIMAX rotated factor analysis and four factors emerged accounting for $67 \%$ of the variance. In accordance with previous studies they were labelled Man Made Problems, Tainted Food, Pollution and Radiation.

\subsection{Correlational and Regression Analyses}

MHW was significantly and positively associated with all five PID-5 domains ( $r \mathrm{~s}$ $=|0.15|-|0.30|)$ and some PID- 5 facets. Table 3 shows the correlations between the five PDs and four MHW factors. Most of the correlations were significant (17/20), all were positive and two were $r>0.4$.

Correlations between the five PDs and the total MHW scale were all significant and between $r=0.18$ and $r=0.38$. This confirms the central thesis of his 
Table 1. Mean Scores per item on the MHW questionnaire compared to other studies.

\begin{tabular}{|c|c|c|c|c|c|}
\hline & $\begin{array}{l}\text { Petrie } \\
\text { et al. } \\
(2001)\end{array}$ & $\begin{array}{c}\text { Furnham } \\
(2007)\end{array}$ & $\begin{array}{c}\text { Jeswani \& } \\
\text { Furnham } \\
(2010)\end{array}$ & $\begin{array}{c}\text { Furnham } \\
\text { et al. } \\
(2012)\end{array}$ & $\begin{array}{l}\text { This } \\
\text { study }\end{array}$ \\
\hline 1. Cell Phones & 2.00 & 1.91 & 2.23 & 1.83 & 2.62 \\
\hline 2. Radio or cell phone towers & 2.25 & 1.93 & 2.33 & 1.75 & 2.46 \\
\hline 3. High tension power lines & 2.31 & 1.96 & 2.38 & 1.78 & 2.55 \\
\hline 4. Nuclear Radiation & & 2.66 & 3.28 & 2.83 & 3.39 \\
\hline 5. Air Pollution & 3.40 & 2.98 & 3.49 & 3.11 & 3.61 \\
\hline 6. Noise Pollution & 2.55 & 2.44 & 2.71 & 2.00 & 2.76 \\
\hline 7. Depletion of ozone layer & 3.60 & 2.86 & 3.53 & 3.06 & 3.53 \\
\hline 8. Traffic fumes & 3.55 & 2.98 & 3.60 & 2.99 & 3.31 \\
\hline 9. Other environmental pollution & 3.40 & 2.85 & 3.53 & 2.93 & 3.45 \\
\hline 10. Pesticide spray & 2.95 & 2.43 & 3.19 & 2.20 & 3.33 \\
\hline 11. Poor building ventilation & 2.70 & 2.08 & 2.87 & 2.13 & 2.83 \\
\hline 12. Genetically modified food & 2.41 & 2.27 & 2.77 & 2.10 & 3.05 \\
\hline 13. Additives in food & 2.50 & 2.43 & 3.07 & 2.32 & 3.31 \\
\hline 14. Pesticides in food & 3.20 & 2.08 & 3.44 & 2.65 & 3.54 \\
\hline 15. Antibiotics in food & 2.80 & 2.27 & 3.25 & 2.50 & 3.36 \\
\hline 16. Hormones in food & 3.00 & 2.43 & 3.39 & 2.77 & 3.37 \\
\hline 17. Mad Cow disease (CJD) & & 2.86 & 2.95 & 2.48 & 2.82 \\
\hline 18. Contaminated water supply & 3.75 & 3.05 & 3.35 & 3.23 & 3.47 \\
\hline 19. Fluoridation in water & 2.30 & 3.02 & 2.49 & 2.27 & 2.86 \\
\hline 20. Vaccination programmes & 2.40 & 2.66 & 2.26 & 2.49 & 2.59 \\
\hline 21. Overuse antibiotics & 3.20 & 2.57 & 3.21 & 3.00 & 3.23 \\
\hline 22. Toxic chemicals in household products & 2.91 & 1.66 & 2.95 & 2.57 & 3.12 \\
\hline 23. Leakage from microwave ovens & 2.60 & 1.77 & 2.19 & 2.20 & 2.49 \\
\hline 24. Bacteria in air conditioning systems & 2.95 & 2.96 & 2.54 & 2.17 & 2.76 \\
\hline 25. Drug resistant bacteria & 3.40 & 2.48 & 3.31 & 3.05 & 3.33 \\
\hline 26. Amalgam dental fillings & 2.25 & 1.72 & 1.91 & 1.65 & 2.37 \\
\hline 27. Medical and dental x-rays & 2.20 & 1.58 & 2.10 & 1.85 & 2.35 \\
\hline 28. Bio-terrorism & & 2.73 & 2.55 & 2.54 & 3.14 \\
\hline 29. Work Stress & & 2.35 & 3.19 & & 3.02 \\
\hline 30. AIDS and similar epidemics & & 2.91 & 3.07 & & 3.03 \\
\hline 31. Passive smoking & & 2.47 & 2.82 & & 2.92 \\
\hline 32. Terrorist attacks on urban populations & & 2.87 & 2.83 & & 3.17 \\
\hline 33. Plane crash & & 1.88 & 2.27 & & 2.80 \\
\hline 34. DNA testing & & 1.58 & 1.92 & & 2.17 \\
\hline 35. Drugs & & 2.52 & 2.53 & & 2.80 \\
\hline
\end{tabular}




\section{Continued}

\begin{tabular}{lccc}
\hline 36. Medical side effects & 2.28 & 2.64 & 2.97 \\
37. Gene therapy & 1.90 & 2.11 & 2.45 \\
38. Human cloning & 2.72 & 2.59 & 2.71 \\
39. Euthanasia & 1.89 & 2.18 & 2.60 \\
40. Overpopulation & 2.51 & 3.15 & 3.14 \\
$\quad$ & & $\mathbf{1 1 2 . 1 5}$ & $\mathbf{1 1 8 . 7 9}$ \\
\hline
\end{tabular}

Table 2. Summary of MHWs factors found in previous MHWs studies.

\begin{tabular}{|c|c|c|c|c|c|c|c|c|c|}
\hline & \multicolumn{9}{|c|}{ Factor } \\
\hline & 1 & 2 & 3 & 4 & 5 & 6 & 7 & 8 & 9 \\
\hline $\begin{array}{l}\text { Furnham et } \\
\text { al(2012) }\end{array}$ & Contamination & $\begin{array}{c}\text { Environmental } \\
\text { Pollution }\end{array}$ & $\begin{array}{c}\text { Food } \\
\text { contamination }\end{array}$ & $\begin{array}{l}\text { Man-made } \\
\text { problems }\end{array}$ & $\begin{array}{l}\text { Medical } \\
\text { Problems }\end{array}$ & & & & \\
\hline $\begin{array}{c}\text { Köteles et al } \\
\text { (2011) }\end{array}$ & $\begin{array}{c}\text { Toxic } \\
\text { Interventions }\end{array}$ & $\begin{array}{c}\text { Environmental } \\
\text { Pollution }\end{array}$ & Tainted Food & Radiation & & & & & \\
\hline $\begin{array}{c}\text { Jeswami \& } \\
\text { Furnham } \\
\text { (2010) }\end{array}$ & $\begin{array}{l}\text { Contamination } \\
\text { with food }\end{array}$ & $\begin{array}{l}\text { Disasters and } \\
\text { epidemics }\end{array}$ & Pollution & $\begin{array}{c}\text { Harmful rays } \\
\text { and air } \\
\text { contamination }\end{array}$ & Radiation & $\begin{array}{l}\text { Doctors } \\
\text { playing } \\
\text { God }\end{array}$ & $\begin{array}{l}\text { Anti-bacterial } \\
\text { medication }\end{array}$ & $\begin{array}{l}\text { Drugs and } \\
\text { medication }\end{array}$ & $\begin{array}{l}\text { Work } \\
\text { Stress }\end{array}$ \\
\hline $\begin{array}{l}\text { Bailer et al } \\
\qquad(2008)\end{array}$ & Radiation & $\begin{array}{c}\text { Environmental } \\
\text { pollution }\end{array}$ & Tainted food & $\begin{array}{c}\text { Toxic } \\
\text { interventions }\end{array}$ & & & & & \\
\hline $\begin{array}{l}\text { Furnham } \\
(2007)\end{array}$ & $\begin{array}{c}\text { Food } \\
\text { contamination }\end{array}$ & Pollution & $\begin{array}{l}\text { Disasters and } \\
\text { Epidemics }\end{array}$ & Harmful rays & $\begin{array}{c}\text { Doctors } \\
\text { playing God }\end{array}$ & Radiation & $\begin{array}{l}\text { Man-made } \\
\text { problems }\end{array}$ & $\begin{array}{c}\text { Safety of health } \\
\text { prevention } \\
\text { issues }\end{array}$ & \\
\hline $\begin{array}{l}\text { Kaptein et al } \\
\quad(2005)\end{array}$ & $\begin{array}{c}\text { Toxic } \\
\text { Interventions }\end{array}$ & $\begin{array}{c}\text { Environmental } \\
\text { Pollution }\end{array}$ & Tainted Food & Radiation & & & & & \\
\hline $\begin{array}{l}\text { Petrie et al } \\
\qquad(2001)\end{array}$ & $\begin{array}{c}\text { Toxic } \\
\text { Interventions }\end{array}$ & $\begin{array}{c}\text { Environmental } \\
\text { Pollution }\end{array}$ & Tainted Food & Radiation & & & & & \\
\hline
\end{tabular}

Table 3. Correlation between the $4 \mathrm{MHW}$ and the 5 PDs.

\begin{tabular}{cccccc}
\hline & Negative Affect & Detachment & Antagonism & Disinhibition & Psychoticism \\
\hline Man Made Problems & $0.17^{* *}$ & 0.05 & $0.19^{* *}$ & $0.12^{*}$ & $0.15^{*}$ \\
Tainted Food & $0.22^{* * *}$ & 0.09 & $0.29^{* * *}$ & $0.17^{* *}$ & $0.24^{* * *}$ \\
Pollution & $0.28^{* * *}$ & 0.11 & $0.28^{* * *}$ & $0.20^{* * *}$ & $0.25^{* * *}$ \\
Radiation & $0.34^{* * *}$ & $0.22^{* * *}$ & $0.43^{* * *}$ & $0.38^{* * *}$ & $0.41^{* * *}$ \\
\hline
\end{tabular}

${ }^{*} p<0.05 ;{ }^{* *} p<0.01 ;{ }^{* *} p<0.001$.

paper that there is a link between the PDs and MHW.

Then five multiple regressions were computed with the four factors, and the Total MHW score as the criterion variable, and sex, age and the five PD variables are predictor variables (see Table 4). The regression onto Man Made Problems showed two PDs were significant and accounted for $8 \%$ of the variance. Those 
Table 4. Results for regression with MHW factors as the Criterion variable.

\begin{tabular}{|c|c|c|c|c|c|c|c|c|}
\hline & \multicolumn{2}{|c|}{$\begin{array}{l}\text { Man Made } \\
\text { Problems }\end{array}$} & \multicolumn{2}{|c|}{ Tainted Food } & \multicolumn{2}{|c|}{ Pollution } & \multicolumn{2}{|c|}{ Radiation } \\
\hline & $\beta$ & $t$ & $\beta$ & $t$ & $\beta$ & $t$ & $\beta$ & $t$ \\
\hline Gender & -0.02 & -0.23 & 0.17 & $2.67^{\star \star}$ & 0.02 & 0.32 & 0.07 & 1.27 \\
\hline Age & 0.06 & 0.99 & 0.14 & $2.21^{\star}$ & -0.08 & -1.30 & -0.03 & -0.53 \\
\hline Negative affect & 0.28 & $2.73^{* *}$ & 0.07 & 0.71 & 0.08 & 0.74 & -0.19 & $-2.03^{*}$ \\
\hline Detachment & -0.18 & $-1.99^{\star}$ & -0.07 & -0.77 & -0.03 & -0.31 & 0.06 & 0.71 \\
\hline Antagonism & 0.06 & 0.54 & 0.06 & 0.57 & 0.16 & 1.48 & 0.35 & $3.61^{* * *}$ \\
\hline Disinhibition & 0.10 & 0.69 & 0.02 & 0.12 & -0.45 & $-2.93^{\star *}$ & -0.17 & -1.26 \\
\hline Psychoticism & 0.03 & 0.29 & -0.06 & -0.36 & 0.23 & 1.38 & 0.45 & $3.10^{\star *}$ \\
\hline R-Square & \multicolumn{2}{|l|}{0.10} & \multicolumn{2}{|l|}{0.05} & \multicolumn{2}{|c|}{0.05} & \multicolumn{2}{|c|}{0.27} \\
\hline $\begin{array}{l}\text { Adjusted } \\
\text { R-square }\end{array}$ & \multicolumn{2}{|l|}{0.08} & \multicolumn{2}{|l|}{0.03} & \multicolumn{2}{|c|}{0.02} & \multicolumn{2}{|c|}{0.25} \\
\hline $\mathrm{F}(7251)$ & \multicolumn{2}{|l|}{$4.08^{\star * *}$} & \multicolumn{2}{|l|}{$2.06^{*}$} & \multicolumn{2}{|c|}{1.75} & \multicolumn{2}{|c|}{$13.15^{* * *}$} \\
\hline
\end{tabular}

${ }^{*} p<0.05 ;{ }^{* *} p<0.01 ;{ }^{* *} p<0.001$.

with more Negative Affect, but less Detachment rated this factor highly. None of the PDs predicted the second factor Tainted Food but the regression showed older females gave higher scores. The third regression onto Pollution showed that those low on Disinhibition gave higher scores. The next regression onto Radiation showed that three PDs were significant and accounted for a quarter of the variance. Those with high Antagonism and Psychoticism but low Negative Affect were more concerned with radiation. A final regression was done with the total MHW score as the criterion. It was significant $(F(7,258)=8.35, p<0.001$; $\operatorname{Adj}^{2}=17$. The only predictor was Antagonism $(\beta=0.30, t=2.98, p<0.001)$. Thus, those who were manipulative, deceitful and grandiose claimed to have higher MHW.

\subsection{Facet Analysis}

Entering the 25 PID-5 facets into a multiple linear regression resulted in a significant regression, but multicollinearity was a limiting issue in this analysis (variance inflation factors $[\mathrm{VIFs}]=2.11-12.38$ ). To minimize the effects of multicollinearity, we used a stepwise regression, with MHW scores entered as the criterion variable and all PID-5 facets as predictors. The final prediction model contained 6 of the 25 predictors and was reached in six steps, with the remaining 19 facets excluded. This model was statistically significant, $F(6,252)=16.38, p<$ 0.001 , Adj. $R^{2}=0.26$. MHW scores were significantly predicted by Unusual Beliefs and Experiences $\left(\beta=0.46, t=4.56, p<0.001\right.$, Adj. $\left.R^{2}=0.15\right)$, Eccentricity $\left(\beta=-0.45, t=4.71, p<0.001\right.$, Adj. $\left.\Delta R^{2}=0.06\right)$, Rigid Perfectionism $(\beta=0.16, t=$ 2.11, $p=0.036$, Adj. $\left.\Delta R^{2}=0.02\right)$, Suspiciousness $(\beta=0.24, t=2.79, p=0.006$, Adj. $\left.\Delta R^{2}=0.01\right)$, Anhedonia $\left(\beta=-0.18, t=-2.34, p=0.020\right.$, Adj. $\left.\Delta R^{2}=0.01\right)$, 
and Emotional Lability $\left(\beta=0.19, t=2.07, p=0.040\right.$, Adj. $\left.\Delta R^{2}=0.01\right)$.

\section{Discussion}

This study confirmed and extended the literature on MHW. Previous studies on the MHW scale in both original and extended form have shown it to have an interpretable factor structure. Similar to previous studies our results showed the MHW questionnaire factored into a number of readily identifiable factors concerning such things as contamination and pollution (see Table 5). They were similar to the four factors labelled Environmental Pollution, Toxic Interventions, Tainted Food and Radiation found by Spangenberg et al. [4] in their modelling of the original scale. These factors are highly positively correlated and it is possible to analyse the data in terms of the total score as well as the separate factors which could yield subtle but important differences. This supports H1.

Further, while there are differences between the responses of the different samples there are consistent patterns whichever sample is used. For instance, all groups are concerned about such issues as drug resistant bacteria and contamination in the water, but relatively little troubled by radio or cell phone towers or noise pollution. The results were very similar to that of Rief et al., [5] who had data on over 2000 German adults.

We did not replicate the demographic findings from previous studies however. Many studies have shown that females have higher MHW scores than males [5] and that older people have higher scores than younger people [9], though studies are consistent. In this study there were neither sex nor age differences in MHW.

There were however also some novel and interesting findings. Participants who rated themselves higher self-perceived health, happiness and success had higher MHW scores. High scores were also associated with not rating oneself as a worrier. To some extent this could be seen as counter intuitive: people who have health worries claim not to be worriers. It is possible that they believe these MHW are shared by many and in some sense an indication of objective facts.

Some studies have shown MHW to be associated with positive affect [7] while others have shown MHW associated with anxiety [29]. However this study may also be explained as a type ofrepressive coping style which is a strategy that involves ignoring or dismissing strong emotions. This repressive coping style concerns individuals' tendency to inhibit the expression of unpleasant cognitions or negative feelings to prevent the self-image of an individual from being threatened [35]. This hypothesis merits further investigation.

The major focus of this study however was on the relationship between the PDs and MHW. All correlational hypotheses were confirmed at the domain and facet level. Previous research on (normal) personality trait correlates of MHW has shown few and weak associations. Thus Furnham et al. [10] found neither Extraversion nor Agreeableness correlated with either MHW total scores or any of the five factors. The most consistent correlation was between trait Openness 
Table 5. Results of the varimax rotated factor analysis.

\begin{tabular}{|c|c|c|c|c|}
\hline \multirow{2}{*}{ Scale Items } & \multicolumn{4}{|c|}{ Component } \\
\hline & 1 & 2 & 3 & 4 \\
\hline Euthanasia & 0.74 & & & \\
\hline AIDS and similar epidemics & 0.72 & & & \\
\hline Gene therapy & 0.72 & & & \\
\hline Plane crash & 0.71 & & & \\
\hline Human cloning & 0.69 & & & \\
\hline Drugs & 0.66 & & & \\
\hline Terrorist attacks on urban populations & 0.65 & & & \\
\hline Medical side effects & 0.62 & & & \\
\hline Bio-terrorism & 0.61 & & & \\
\hline Passive smoking & 0.60 & & & \\
\hline DNA testing & 0.59 & & & \\
\hline Bacteria in air conditioning systems & 0.53 & & & \\
\hline Work Stress & 0.52 & & & \\
\hline Mad Cow disease (CJD) & 0.50 & 0.48 & & \\
\hline Antibiotics in food & & 0.81 & & \\
\hline Hormones in food & & 0.80 & & \\
\hline Additives in food & & 0.78 & & \\
\hline Pesticides in food & & 0.76 & & \\
\hline Genetically modified food & & 0.76 & & \\
\hline Toxic chemicals in household products & & 0.52 & & \\
\hline Contaminated water supply & & 0.51 & & \\
\hline Fluoridation in water & & 0.51 & & \\
\hline Poor building ventilation & & 0.48 & & \\
\hline Other environmental pollution & & & 0.81 & \\
\hline Air pollution & & & 0.76 & \\
\hline Depletion of ozone layer & & & 0.76 & \\
\hline Traffic fumes & & & 0.75 & \\
\hline Pesticide spray & & & 0.63 & \\
\hline Drug resistant bacteria & & & 0.49 & \\
\hline Overpopulation & & & 0.45 & \\
\hline Overuse of antibiotics & & & 0.43 & \\
\hline Nuclear radiation & & & 0.38 & \\
\hline Radio or cell phone towers & & & & 0.77 \\
\hline Cell phones & & & & 0.76 \\
\hline High tension power lines & & & & 0.73 \\
\hline
\end{tabular}




\section{Continued}

\begin{tabular}{cccc}
\hline $\begin{array}{c}\text { Medical and dental x-rays } \\
\text { Vaccination programs }\end{array}$ & & 0.66 \\
Amalgam dental fillings & & 0.62 \\
Leakage from microwave ovens & & & 0.58 \\
Noise pollution & & & 0.56 \\
Eigenvalue & 21.23 & 2.52 & 0.50 \\
Percentage of Total Variance & 53.08 & 6.30 & 4.33 \\
\hline
\end{tabular}

and the factor scores though they were modest $(0.12<r<0.31 ; N=301)$. In this study we showed as predicted that there were positive correlations between the five PDs and their facets with total MHW scores though none was $r>0.40$.

However, the most important results were in the regression. The regression showed that the various MHW factors were related to different PDs, and Antagonism was the only significant predictor of the total scale. The facet level analysis showed the significant facets came from each of the five domains though the strongest association was with Unusual Beliefs and Experiences which is linked to trait Openness and Schizotypal traits. This suggests that in some ways MHWs are "unusual beliefs" that certain people are happier to entertain than others. The second most powerful predictor was Suspiciousness which also makes sense in that some would consider belief in MHWs a sign of mild paranoia.

However, this like all other studies seems not to find strong and clear individual difference correlates of MHWs which suggests they might be more related to social or cultural factors rather than individual difference factors. In this sense these MHWs seem to be shared although it is apparent from the standard deviations in ratings in all studies that there are important and significant differences between people.

\section{Study 2}

In this study we used the original version of the MHW scale but a very different measure of PDs. Whereas in the first study we used a very new measure based on DSM-V, in this study we used a questionnaire based on earlier DSM classification of PDs. It assesses 14 PDs and is described below. Based on their individual characteristics we hypothesized that three PDs, namely Paranoid, Schizotypal and Borderline would be most closely related to MHWs measured at both domain and facet level.

This study also sought to examine two other correlates of MHWs. The first was optimism vs pessimism. Examining the MHW literature suggests that those who are more anxious and depressed are prone to worry about all things including the health environment. In this study we simply asked participants to what extent they were, in general optimistic, investigating whether these single items would account for any variance in MHW. Hence it was predicted that Optimism would be negatively related to MHW. 
Finally, many MHW debates are highly political in nature, particularly the cause of the environmental problems. As yet no studies have examined political correlates of MHW. We assumed that concern with, and proposed intervention in, environmental issues are more associated with left-wing, than right-wing politics. It was predicted that the more left-wing/liberal people are the more they would be concerned with MHW.

We also predicted that a factor analysis of the scale would yield the same four interpretable structures. Also we predicted that the Cluster B, PDs would be most consistently associated with the MHW scale scores.

\section{Method}

\subsection{Participants}

In total, 402 participants completed the questionnaire (53\% females, age range: 19 to 76 years, $M_{\text {age }}=31.6$ years, $S D_{\text {age }}=13.5$. In all $27 \%$ had a high school qualification and $48 \%$ an undergraduate degree and $21 \%$ some postgraduate qualification.

\subsection{Materials \& Procedure}

1) Modern Health Worries. The MHWs scale is a 28 -item five-point scale. Items (e.g. Food additives, Air Pollution, etc) are rated from "No Concern at all" to "Extreme Concern" that the item will affect one's personal health. Certain words in the item list, such as 'cell phone' were exchanged for 'mobile phone' to better suit the language of British participants. Further, based on earlier research that attempted to update the 15 year old original 25 item measure three items were added: "Mad Cow Disease", "Bio-Terrorism" and "Nuclear Radiation".

2) Personality Disorders. All respondents completed the 70-item Coolidge Axis-II Inventory-Short Form (SCATI) [36] [37]. The self-report measure assesses 14 personality disorders, 10 from $D S M-V, 2$ from Cluster $\mathrm{B}$ of the $D S M-I V$-TR (depressive and passive-aggressive) and 2 from DSM-III-R (sadistic and self-defeating). Items concerning the 4 PDs from previous versions of the diagnostic manual were excluded, resulting in a 50-item measure. The SCATI has good internal scale and test-retest reliability [38]. It has been used to predict PDs in subclinical [37] and clinical [39] populations. It has been used in various recent studies [40].

3) Demographics (age, sex, education). They were also asked to rate whether they were an optimist $(1=$ Strongly Agree to $7=$ Strongly Disagree) (Mean $=4.98$, $\mathrm{SD}=1.55)$. They also rated their political beliefs on a 7 point scale $(1=$ Very Left-Wing/Liberal; 7 = Very Right-Wing Conservative $)($ Mean $=3.69, \mathrm{SD}=1.77)$.

\subsection{Procedure}

Ethical permission was sought and received from the relevant Ethics committee. The entire questionnaire was administered online via Amazon Turk, where respondents were paid $\$ 1.00$ each for taking part. Inspection of the data meant a 
number of participants were removed as they had either not completed the questionnaire or filled it out in less than 5 minutes which was considered an appropriate time to take the test seriously.

\section{Results}

First the MHW questionnaire was subject to a Varimax rotated factor analysis (Table 6). This yielded four clear factors which accounted for just under three

Table 6. Results of the varimax rotated factor analysis of the MHW scale.

\begin{tabular}{|c|c|c|c|c|}
\hline \multirow{2}{*}{ Scale Items } & \multicolumn{4}{|c|}{ Component } \\
\hline & 1 & 2 & 3 & 4 \\
\hline Other environmental pollution & 0.81 & & & \\
\hline Air Pollution & 0.80 & & & \\
\hline Depletion of Ozone layer & 0.78 & & & \\
\hline Traffic fumes & 0.76 & & & \\
\hline Pesticide spray & 0.61 & & & \\
\hline Poor building ventilation & 0.55 & & & \\
\hline Noise pollution & 0.54 & & & \\
\hline Nuclear radiation & 0.54 & & & \\
\hline Hormones in food & & 0.82 & & \\
\hline Additives in food & & 0.82 & & \\
\hline Antibiotics in food & & 0.81 & & \\
\hline Pesticides in food & & 0.76 & & \\
\hline Genetically modified food & & 0.66 & & \\
\hline Toxic chemicals & & 0.56 & & \\
\hline Overuse of antibiotics & & 0.52 & & \\
\hline Bio terrorism & & & 0.76 & \\
\hline CJD & & & 0.72 & \\
\hline Bacteria in air conditioning systems & & & 0.67 & \\
\hline Contaminated water supply & & & 0.63 & \\
\hline Leakage from microwave ovens & & & 0.59 & \\
\hline Fluoridation of water & & & 0.54 & \\
\hline Drug resistant bacteria & & & 0.48 & \\
\hline Radio cell phone tower & & & & 0.83 \\
\hline Cell phones & & & & 0.80 \\
\hline High tension power lines & & & & 0.72 \\
\hline Medical dental $\mathrm{X}$ rays & & & & 0.59 \\
\hline Amalgam dental fillings & & & & 0.55 \\
\hline Vaccination programmes & & & & 0.55 \\
\hline Eigenvalue & 5.61 & 5.31 & 5.10 & 4.35 \\
\hline Percentage of Total Variance & 20.10 & 18.97 & 18.17 & 15.54 \\
\hline
\end{tabular}


quarters of the variance. The factors made sense and were labelled: Environmental Pollution, Tainted Food, Contamination and Harmful Rays. Four scores were then computed for each factor.

A sex-difference one-way ANOVA was computed on each factor score as well as the total MHW scale. Results showed a significant sex difference on every factor where females scored higher than males: Environmental Pollution $(F(1$, $391)=9.63, p<0.01)$; Tainted Food $(F(1,400)=28.59, p<0.001)$; Contamination $(F(1,397)=9.72, p<0.01)$ and Harmful Rays $(F(1,400)=17.28, p<$ $0.001)$. The Anova for the total score was not significant. Three of the five MHW scale scores significantly correlated with pessimism which provides partial support for the hypotheses. Similarly, only one of the five correlations was significant for political beliefs showing minimal support for that hypothesis

Table 7 also shows the correlations between the four MHW scores and the 14PDs. The results showed six of the PDs were unrelated to the MHW: Antisocial, Avoidant, Dependent, Depressive, Passive-Aggressive and Schzoid. Equally two PDs were positively correlated with the four MHW: Paranoid and Schizotypal. The final factor (F4: Harmful Rays) was significantly correlated with 8/14

Table 7. Correlations between the four MHW factors and the 14PDs.

\begin{tabular}{|c|c|c|c|c|c|}
\hline & $F 1: E P$ & $F 2: T F$ & F3:Con & $F 4: H R$ & TOT \\
\hline F2 & $0.78^{* *}$ & & & & \\
\hline F3 & $0.78^{* *}$ & $0.51^{\star \star}$ & & & \\
\hline F4 & $0.65^{\star *}$ & $0.76^{* *}$ & $0.77^{\star \star}$ & & \\
\hline Antisocial & 0.03 & 0.02 & 0.07 & 0.07 & 0.03 \\
\hline Avoidant & 0.06 & 0.01 & 0.05 & 0.01 & 0.04 \\
\hline Borderline & 0.09 & 0.06 & $0.14^{\star *}$ & $0.12^{*}$ & 0.09 \\
\hline Dependent & 0.01 & -0.04 & 0.08 & $0.11^{*}$ & 0.03 \\
\hline Depressive & 0.04 & 0.04 & 0.04 & -0.02 & 0.03 \\
\hline Histrionic & 0.06 & 0.04 & $0.14^{* *}$ & $0.15^{\star *}$ & 0.09 \\
\hline Narcissistic & $0.14^{* *}$ & 0.10 & $0.20^{\star \star}$ & $0.19^{* *}$ & $0.15^{\star *}$ \\
\hline Obsessive Compulsive & $0.17^{\star \star}$ & 0.09 & $0.15^{\star *}$ & $0.12^{*}$ & $0.13^{* *}$ \\
\hline Paranoid & $0.13^{\star \star}$ & $0.12^{*}$ & $0.18^{\star \star}$ & $0.15^{\star *}$ & $0.15^{\star *}$ \\
\hline Passive Aggressive & $0.11^{*}$ & 0.04 & 0.09 & 0.05 & 0.07 \\
\hline Sadistic & 0.02 & 0.01 & $0.13^{*}$ & $0.15^{\star *}$ & 0.06 \\
\hline Self-defeating & 0.09 & 0.03 & 0.09 & 0.07 & 0.08 \\
\hline Schizotypal & $0.14^{* *}$ & $0.11^{*}$ & $0.24^{\star *}$ & $0.21^{\star *}$ & $0.18^{\star *}$ \\
\hline Schizoid & 0.04 & -0.03 & 0.03 & -0.01 & 0.01 \\
\hline Optimism/Pessimism & 0.03 & 0.09 & $0.10^{\star *}$ & $0.19^{\star \star}$ & $0.12^{*}$ \\
\hline Politics & -0.08 & $-0.25^{\star *}$ & -0.07 & 0.02 & 0.00 \\
\hline
\end{tabular}

${ }^{* *} p<0.01 ;{ }^{*} p<0.05$. Significant Correlations are in Bold. $\mathrm{EP}=$ Environmental Pollution; $\mathrm{TF}=\mathrm{Tainted}$ Food ; Con $=$ Contamination HR $=$ Harmful Rays; TOT $=$ Total MHWs 
PDs while the second factor (F2: Tainted Food) was only significantly related with two PDs.

The correlations show that both those with subclinical Paranoid and Schizotypal PD have all four types of MHW while those with Narcissistic and Obsessive-Compulsive PD worry about three of the four factors.

Following this, five stepwise multiple regressions were computed with each of the four factors and the total MHW scale being the criterion variable (See Table 8). In the first step sex, age and education were entered; the second step included optimism and politics and the third step the 14 PDs. All regressions were significant. For Environmental Pollution $\left(F(19,335)=3.99, p<0.001, \operatorname{Adj}^{2}=0.14\right)$ there were three significant variables: Sex (beta $=0.19, t=3.45, p<0.001$; Political views (beta $=-0.27 ; t=5.11, p<0.001$; Obsessive Compulsive PD (beta $=$ $0.15, t=2.10, p<0.05)$. For Tainted Food $\left(F(19,335)=3.19, p<0.001, \operatorname{Adj}^{2}=\right.$ 0.11 ) there were four significant variables: Sex (beta $=0.22 ; t=3.97, p<0.010$; Age (beta $=0.13, t=2.27, p<0.05)$; Optimism (beta $=0.19, t=2.65, p<0.01$ ) and politics (beta $=-0.11, t=2.10, p<0.05)$. For Contamination $(F(19,335)=$ 3.55, $p<001$, Adj $\left.\mathrm{R}^{2}=0.12\right)$ there were three significant variables: Sex (beta $=$ 0.23 ; $t=4.10, p<0.001$ ); Optimism (beta $=0.17, t=2.33, p<0.05$ ) and Schizotypal (beta $=0.18, \mathrm{t}=2.36, \mathrm{p}<0.01$. For Harmful Rays $(F(19,335)=3.30, p<$ $0.001, \mathrm{Adj}^{2}=0.11$ ) there were only two significant variables: Sex (beta $=0.14, t$ $=2.55, p<0.01)$ and optimism (beta $=0.25, \mathrm{t}=3.49, \mathrm{p}<0.001)$. For the Total

Table 8. Results of the Varimax Rotated Factor Analysis of the PD Scale.

\begin{tabular}{|c|c|c|}
\hline \multirow{2}{*}{ Scale Items } & \multicolumn{2}{|c|}{ Component } \\
\hline & 1 & 2 \\
\hline Depressive & 0.90 & \\
\hline Avoidant & 0.86 & \\
\hline Schizoid & 0.80 & \\
\hline Self-Defeating & 0.79 & \\
\hline Borderline & 0.70 & \\
\hline Passive Aggressive & 0.70 & \\
\hline Paranoid & 0.69 & \\
\hline Dependent & 0.68 & \\
\hline Histrionic & & 0.86 \\
\hline Narcissistic & & 0.83 \\
\hline Sadistic & & 0.70 \\
\hline Schizotypal & & 0.63 \\
\hline Antisocial & & 0.61 \\
\hline Obsessive Compulsive & 0.43 & 0.48 \\
\hline Eigenvalue & 7.95 & 1.54 \\
\hline Percentage of Total Variance & 56.79 & 11.00 \\
\hline
\end{tabular}


MHW scale $\left(F(19,335)=3.56 p<0.001, \operatorname{AdjR}^{2}=0.12\right)$ there were three significant variables: Sex (beta $=0.22 ; t=3.82, p<0.001$ ), Optimism (beta $=0.23, t=$ 3.10, $p<0.001$ ) and Politics (beta $=0.12, t=2.28, p<0.05$ ). The results were thus clear: whilst the PDs increased the variance accounted for in the last step by around $4 \%$ of the variance sex, optimism and political views accounted for most of the variance.

Because of the problems of multicollinearity with the 14 PD scales they were then subject to a Varimax rotation factor analysis. This resulted in two factors which accounted for two thirds of the variance. Obsessive Compulsive loaded on both dimensions. The first was essentially a combination of Cluster A or what Horney and Hogan call "Moving Away from Others" while the second was clearly Cluster B or "Moving Against Others" [41]. The items were then computed to form two scores.

Following this a step-wise regression was performed with demographics entered first (sex, age, education), then optimism, then politics, then the two PD scores (see Table 9). The pattern was very clear across the four factor scores and the total score. All five regressions were significant and accounted for similar amounts of variance (around 12\%). In each regression sex was always significant indicating the well-established pattern that females have more MHW than males. Similarly Factor 2, Moving against people was positively associated with each MHW.

For the first regression results indicated that left-wing, Moving against others females were most concerned with environmental pollution. The results were similar for the second factor Tainted Food except being an older pessimist also played a role. The final three regressions showed similar results where sex, pessimism and Moving against Others PDs were the strongest predictor.

\section{Discussion}

This study revealed, as hypothesized, that MHWs is a multi-factoral construct.

Table 9. Regression results with the MHW scale as the dependent variable.

\begin{tabular}{|c|c|c|c|c|c|c|c|c|c|c|}
\hline & \multicolumn{2}{|c|}{$F 1: E P$} & \multicolumn{2}{|c|}{$F 2: T F$} & \multicolumn{2}{|c|}{ F3:Con } & \multicolumn{2}{|c|}{$F 4: H R$} & \multicolumn{2}{|c|}{$T O T$} \\
\hline & Beta & $t$ & Beta & $t$ & Beta & $t$ & Beta & $t$ & Beta & $t$ \\
\hline Sex & $0.21^{\star * *}$ & 3.20 & $0.25^{* * *}$ & 4.77 & $0.25^{\star * *}$ & 4.77 & $0.17^{\star *}$ & 3.26 & $0.25^{\star *}$ & 4.68 \\
\hline Age & 0.09 & 1.64 & $0.13^{* *}$ & 2.39 & 0.06 & 1.17 & 0.02 & 0.33 & 0.02 & 0.41 \\
\hline Education & 0.02 & 0.03 & 0.04 & 0.70 & -0.02 & 0.36 & 0.04 & 0.87 & 0.11 & 1.96 \\
\hline Optimist (Low score) & 0.12 & 1.83 & $0.13^{*}$ & 2.05 & $0.15^{\star}$ & 2.39 & $0.25^{\star * *}$ & 3.81 & $0.20^{* *}$ & 2.97 \\
\hline Political Orientation & $-0.27^{\star * *}$ & 5.41 & $-0.10^{*}$ & 2.02 & -0.02 & 0.30 & -0.06 & -1.11 & -0.11 & 2.19 \\
\hline FF1: Moving Away & 0.01 & 0.08 & -0.02 & 0.25 & -0.02 & 0.21 & 0.01 & 0.11 & 0.03 & 0.26 \\
\hline FF2; Moving Against & $0.22^{* *}$ & 2.59 & $0.26^{\star *}$ & 2.69 & $0.32^{\star * *}$ & 3.87 & $0.27^{\star *}$ & 3.26 & $0.25^{\star \star}$ & 2.90 \\
\hline $\mathrm{F}(10,337)$ & \multicolumn{2}{|c|}{$5.17^{* * *}$} & \multicolumn{2}{|c|}{$4.64^{* * *}$} & \multicolumn{2}{|c|}{$6.22^{* * *}$} & \multicolumn{2}{|c|}{$5.88^{\star *}$} & \multicolumn{2}{|c|}{$7.72^{* * *}$} \\
\hline AdjR (Square) & \multicolumn{2}{|c|}{0.12} & \multicolumn{2}{|c|}{0.10} & \multicolumn{2}{|c|}{0.13} & \multicolumn{2}{|c|}{0.12} & \multicolumn{2}{|c|}{0.12} \\
\hline
\end{tabular}

$\mathrm{EP}=$ Environmental Pollution; $\mathrm{TF}=$ Tainted Food Con = Contamination; HR = Harmful Rays; TOT $=$ Total MHW. 
The factor analysis on MHWs revealed four factors which is also in line with Furnham et al. [10]. In addition, the cluster of items that constitute each factor (particularly Factors 1 through 3) overlap with those defined in previous studies increasing the validity of the findings of this study.

The correlational analysis showed how specific PDs were and were not related to the MHW factors and total score. In all, six of the PDs were unrelated to the MHW: Antisocial, Avoidant, Dependent, Depressive, Passive-Aggressive and Schzoid. It is interesting to note that these PDs came from each of the three Clusters A, B and C. Equally two PDs were positively all correlated with the four MHW: Paranoid and Schizotypal. It is not difficult to explain why these two factors are related to MHW.

First Schizotypal: Oldham and Morris [42], who call these subclinical schizotypal PD idiosyncratic who are tuned in to, and sustained by, their own feelings and belief systems, They create interesting, unusual, often eccentric lifestyles and are pen to anything, they are interested in the occult, the extrasensory, and the supernatural. It is not difficult to see schizotypal individuals have MHW based on their view of the world.

Next paranoia: According to Oldham and Morris [42] they are careful in their dealings with others, preferring to evaluate a person before entering into a relationship They are good listeners, with an ear for subtlety, tone, and multiple levels of communication, are feisty and do not hesitate to stand up for themselves, especially when they are under attack. Clearly paranoid people are sensitive to, and worried about, others and the physical environment which can cause them harm: and hence their increased MHW scores on all factors.

It is interesting to note two other PDs which correlated significantly with the MHW. The first is Obsessive-Compulsive who are characterised by perfectionism, prudence and need for order. Often their concerns with cleanliness and control mean that they get worried and frustrated by environmental factors beyond their control.

It is however not quite so clear as to why Narcissism was so consistently related to MHW. The two dimensions of NPD are often referred to as grandiose and vulnerable narcissism. Grandiose narcissism is associated with grandiosity, aggression, and dominance, whereas vulnerable narcissism is a defensive, insecure grandiosity that hides feelings of inadequacy, incompetence and negative effect. Both dimensions of narcissism show a tendency to act antagonistically towards others and that they differ on many other features. Vulnerable narcissists have grandiose fantasies but are timid, insecure and consequently do not appear narcissistic on the surface. Grandiose narcissists have higher levels of happiness and life satisfaction and are more exhibitionistic than vulnerable narcissists.

The results for optimism-pessimism were particularly interesting. The correlations results showed three, and the regression results four of the five analyses were significant all showing that the more people rated themselves very simply 
on a simple 7 point Optimism scale the more they had MHW. It is not clear whether MHW increased pessimism or that being pessimistic means that people worry about all sorts of things including threats to their health.

The results for political beliefs were less strong: The correlational analysis show one and the regression analysis two significant results with more left wing people having more $\mathrm{MHW}$ on factors one and two.

Finally, the regression results for the five criterion variables were very consistent. First, the predictor variables accounted for around a tenth of the variance in each. Three of the predictors were consistently significant suggesting that pessimistic, females with predominantly Cluster B PDs were more likely to have MHWs. It is interesting to note that neither age nor education were strongly linked to the MHWs.

This study had limitations. It was a cross-sectional self-report study meaning both that causation cannot not inferred and that common method variance may inflate the correlations. Further, other PD measures may have been used which are more robust. However like many other studies in the MHW area it provided some additional light on who and why people have MHWs.

\section{Overall Conclusion}

There are three overall points that can be made from these two studies. The first is that the factor structure of the original and extended MHW scale is very robust across many groups. Although different labels are used in different studies (see Tables 2-4) there are clear and related factors that make up MHW. Studies have shown slightly different correlates of the scales. This appears therefore to be a robust multi-dimensional construct.

Second, that however one measures the PDs, that whilst they are modestly correlated with MHW those associations, like those of personality traits, are relatively small. That is, correlations are modest but nearly all positive (see Table 4 and Table 7). However, once the PDs are entered into a regression few are significant. However, it does appear that some PDs associated with Schizotypy/Psychoticism are systematically linked to many MHWs. Many studies have looked at individual difference correlates of $\mathrm{MHW}$ to try to understand how these health concerns arise and perseverate however almost no study, including this has shown evidence of any traits accounting for very much (over 10\%) of the variance.

Third, although we did not replicate sex effects in the two studies, simple questions measuring the extent to which a person is happy or optimistic may be strongly linked to MHW. Indeed, these questions are also related to the PDs and account for more of the variance. These may indicate that state, as much as trait factors, are associated with MHW.

\section{Conflicts of Interest}

The author declares no conflicts of interest regarding the publication of this paper. 


\section{References}

[1] Petrie, K., Broadbent, E., Kley, N., Moss-Morris, R., Horne, R. and Rief, W. (2005) Worries about Modernity Predict Symptom Complaints after Environmental Pesticide Spraying. Psychosomatic Medicine, 67, 778-782. https://doi.org/10.1097/01.psy.0000181277.48575.a4

[2] Petrie, K., Silvertsen, B., Hysing, M., Broadbent, E., Moss-Morris, R., Eriksen, H. and Ursin, H. (2001) Thoroughly Modern Worries: The Relationship of Worries about Modernity to Reported Systems, Health and Medical Care Utilization. Journal of Psychosomatic Research, 51, 395-401. https://doi.org/10.1016/S0022-3999(01)00219-7

[3] Furnham, A. (2007) Are Modern Health Worries, Personality and Attitudes to science Associated with the Use of Complementary and Alternative Medicine? British Journal of Health Psychology, 12, 229-243. https://doi.org/10.1348/135910706X100593

[4] Spangenberg, L., Zenger, M., Rief, W., Brahler, E. and Glaesmer, H. (2014) Assessing Modern Health Worries. Journal of Health Psychology, 19, 1302-1308. https://doi.org/10.1177/1359105313488980

[5] Rief, W., Glaesmer, H., Baehr, V., Broadbent, E., Brahler, E. and Petrie, K. (2012) The Relationship of Modern Health Worries to Depression, Symptom Reporting and Quality of Life in a General Population Survey. Journal of Psychosomatic Research, 72, 318-320. https://doi.org/10.1016/j.jpsychores.2011.11.017

[6] Spink, G., Green, T. and Jorgensen, R. (2014) Openness Moderates the Relationship between Modern Health Worries and Neuroticism. Personality and Individual Differences, 70, 35-38. https://doi.org/10.1016/j.paid.2014.06.010

[7] Koteles, F. and Simor, P. (2014) Modern Health Worries, Somatosensory Amplification, Health Anxiety and Well-Being. European Journal of Mental Health, 9, 20 33. https://doi.org/10.5708/EJMH.9.2014.1.2

[8] Buhrmester, M., Kwang, T. and Gosling, S.D. (2011) Amazon's Mechanical Turk a New Source of Inexpensive, Yet High-Quality, Data? Perspectives on Psychological Science, 6, 3-5. https://doi.org/10.1177/1745691610393980

[9] Andersen, J. and Jensen, J. (2012) Modern Health Worries and Visits to the General Practitioner in a General Population Sample. Journal of Psychosomatic Research, 73, 264-267. https://doi.org/10.1016/j.jpsychores.2012.07.007

[10] Furnham, A., Strait, L. and Hughes, D. (2012) Modern Health Worries and Personality. Personality and Mental Health, 6, 242-254. https://doi.org/10.1002/pmh.1187

[11] Fionda, S. and Furnham, A. (2014) Hypochondriacal Attitudes and Beliefs, Attitudes towards Complementary and Alternative Medicine and Modern Health Worries Predict Patient Satisfaction. Journal of the Royal Society of Medicine Open, 5 , 1-10. https://doi.org/10.1177/2054270414551659

[12] Witthoft, M., Freitag, I., Nussbaum, C., Brascher, A-K., Jasper, F., Bailer, J. and Rubin, G. (2017) On the Origin of Worries about Modern Health Hazards. Psychology and Health, 33,1-20.

[13] Koteles, F., Barany, E., Varsanyi, P. and Bardos, G. (2012) Are Modern Health Worries Associated with Somatosensory Amplification, Environmental Attribution Style, and Commitment to Complementary and Alternative Medicine? Scandinavian Journal of Psychology, 53, 144-149. https://doi.org/10.1111/j.1467-9450.2011.00908.x

[14] Baliatsas, C., van Kemp, I., Hooiveld, M., Lebret, E. and Yzermans, J. (2015) The 
Relationship of Modern Health Worries to Non-Specific Physical Symptoms and Perceived Environmental Sensitivity. Journal of Psychosomatic Research, 79, 355 361. https://doi.org/10.1016/j.jpsychores.2015.09.004

[15] Indregard, A-M., Ihlebaek, C. and Eriksen, H. (2013) Modern Health Worries, Subjective Health Complaints, Health Care Utilization and Sick Leave in the Norwegian Working Population. International Journal of Behaviour Medicine, 20, 371-377. https://doi.org/10.1007/s12529-012-9246-1

[16] Palmquist, E., Petrie, K. and Nordin, S. (2017) Psychometric Properties and Normative Data for Swedish Version of the Modern Health Worries. International Journal of Behavioural Medicine, 24, 54-65. https://doi.org/10.1007/s12529-016-9576-5

[17] Chen, M. F. (2011) The Mediating Role of Subjective Health Complaints on Willingness to Use Selected Functional Foods. Food Quality and Preference, 22, 110 118. https://doi.org/10.1016/j.foodqual.2010.08.006

[18] Ozakinki, G., Boratav, H. and Mora, P. (2011) Modern Health Worries, Health Care Utilization and Symptom Reporting. Behavioral Medicine, 37, 35-41. https://doi.org/10.1080/08964289.2011.552925

[19] Bailer, J., Witthoft, M. and Rist, F. (2008) Modern Health Worries and Idiopathic Environmental Intolerance. Journal of Psychosomatic Research, 65, 425-433. https://doi.org/10.1016/j.jpsychores.2008.05.006

[20] Devcich, D., Pedersen, I. and Petrie, K. (2007) You Eat What You Are: Modern Health Worries and the Acceptance of Natural and Synthetic Additives in Functional Foods. Appetite, 48, 333-337. https://doi.org/10.1016/j.appet.2006.09.014

[21] Filipkowski, K., Smyth, J., Rutchick, A., Santuzzi, A., Adya, M., Petrie, K. and Kaptein, A. (2009) Do Health People Worry? Modern Health Worries, Subjective Health Complaints, Perceived Health, and Health Care Utilization. International Journal of Behaviour and Medicine, 17, 182-188. https://doi.org/10.1007/s12529-009-9058-0

[22] Jeswani, M. and Furnham, A. (2010) Are Modern Health Worries, Environmental concerns, or Paranormal Beliefs Associated with Perceptions of the Effectiveness of Complementary and Alternative Medicine? British Journal of Health Psychology, 15, 599-609. https://doi.org/10.1348/135910709X477511

[23] Köteles, F., Szemerszky, R., Freyler, A. and Bárdos, G. (2011) Somatosensory Amplification as a Possible Source of Subjective Symptoms behind Modern Health Worries. Scandinavian Journal of Psychology, 52, 174-178. https://doi.org/10.1111/j.1467-9450.2010.00846.x

[24] Köteles, F. and P. Simor (2013) 'Modern Health Worries, Somatosensory Amplification and Subjective Symptoms: A Longitudinal Study'. International Journal of Behavioral Medicine, 20, 38-41. https://doi.org/10.1007/s12529-011-9217-y

[25] Lahrach, Y. and Furnham, A. (2017) Are Modern Health Worries associated with Medical Conspiracy Theories? Journal of Psychosomatic Research, 99, 89-94. https://doi.org/10.1016/j.jpsychores.2017.06.004

[26] Lind, R., Arsland, G., Eriksen, H., Kahrs, G., Haug, T., Florvaag, E. and Berstad, A. (2005) Subjective Health Complaints and Modern Health Worries in Patients with Subjective Food Hypersensitivity. Digestive Diseases and Sciences, 50, 1245-1251. https://doi.org/10.1007/s10620-005-2767-6

[27] Rubin, G.J., Cleare, A. and Wesseley, S. (2008) Psychological Factors Associated with Self-Reported Sensitivity to Mobile Phones. Journal of Psychosomatic Research, 64, 1-9. https://doi.org/10.1016/j.jpsychores.2007.05.006

[28] Strait, L. and Furnham, A. (2012) The effects of Modern Health Worries and Psy- 
chological Distress on Complementary Medicine Use by Breast Cancer Patients. Clinical Research and Bioethics, 3, Article No. 1000126. https://doi.org/10.4172/2155-9627.1000126

[29] Freyler, A., Kohegyi, Z., Koteles, F., Kokonyei, G. and Bardos, G. (2013) Modern Health Worries, Subjective Somatic Symptoms, Somatosensory Amplification and Health Anxiety in Adolescents. Journal of Health Psychology, 18, 773-781. https://doi.org/10.1177/1359105313479629

[30] Samuel, D. and Widiger, T. (2008) A Meta-Analysis of the Relationships between the Five-Factor Model and DSM-IV-TR Personality Disorders. Clinical Psychology Review, 28, 1326-1342. https://doi.org/10.1016/j.cpr.2008.07.002

[31] Furnham, A., Milner, R., Akhtar, R. and Fruyt, F. (2014) A Review of the Measures Designed to Assess DSM-5 Personality Disorders. Psychology, 5, 1646-1686.

https://doi.org/10.4236/psych.2014.514175

[32] Krueger, R.F., Derringer, J., Markon, K.E., Watson, D. and Skodol, A.E. (2012) Initial Construction of a Maladaptive Personality Trait Model and Inventory for DSM-5. Psychological Medicine, 42, 1879-1890.

https://doi.org/10.1017/S0033291711002674

[33] Wright, A.G., Thomas, K.M., Hopwood, C.J., Markon, K.E., Pincus, A.L. and Krueger, R.F. (2012) The hierarchical Structure of DSM-5 Pathological Personality traits. Journal of Abnormal Psychology, 121, 951-957.

https://doi.org/10.1037/a0027669

[34] Swami, V., Chamorro-Premuzic, T. and Furnham, A. (2010) Unanswered questions: A Preliminary Investigation of Personality and Individual Difference Predictors of 9/11 Conspiracist Beliefs. Applied Cognitive Psychology, 24, 749-761. https://doi.org/10.1002/acp.1583

[35] Furnham, A., Petrides, K.V., Sisterson, G. and Baluch, B. (2003) Repressive Coping Style and Positive Self-Presentation. British Journal of Health Psychology, 8, 223249. https://doi.org/10.1348/135910703321649187

[36] Coolidge, F.L. and Merwin, M.M. (1992) Reliability and Validity of the Coolidge Axis II Inventory: A New Inventory for the Assessment of Personality Disorders. Journal of Personality Assessment, 59, 223-238. https://doi.org/10.1207/s15327752jpa5902 1

[37] Coolidge, F.L., Segal, D.L., Cahill, B.S. and Simenson, J.T. (2010) Psychometric Properties of a Brief Inventory for the Screening of Personality Disorders: The SCATI. Psychology and Psychotherapy: Theory, Research and Practice, 83, 395-405. https://doi.org/10.1348/147608310X486363

[38] Sinha, B.K. and Watson, D.C. (2007) Personality Disorder in University Students: A Multitrait-Multimethod Matrix Study. Journal of Personality Disorders, 15, 235 244. https://doi.org/10.1521/pedi.15.3.235.19205

[39] Watson, D.C. and Sinha, B.K. (1996) A normative study of the Coolidge Axis II Inventory. Journal of Clinical Psychology, 52, 631-637. https://doi.org/10.1002/(SICI)1097-4679(199611)52:6<631::AID-JCLP5>3.0.CO;2-N

[40] Davison, M. and Furnham, A. (2018) The Personality Disorder Profile of Professional Actors. Psychology of Popular Media and Culture, 7, 33-46. https://doi.org/10.1037/ppm0000101

[41] Furnham, A. (2015) Backstabbers and Bullies. Bloomsbury, London.

[42] Oldham, J. and Morris, L. (2000) Personality Self Portrait. Bantam, New York 